University of Nebraska - Lincoln

DigitalCommons@University of Nebraska - Lincoln

Public Health Resources

Public Health Resources

2016

The epidemiology and outcomes of invasive Candida infections among organ transplant recipients in the United States: results of the Transplant-Associated Infection Surveillance Network (TRANSNET)

David R. Andes

University of Wisconsin - Madison

Nasia Safdar

University of Wisconsin - Madison

John W. Baddley

University of Alabama, Birmingham

Barbara Alexander

Duke University School of Medicine

Lisa Brumble

Mayo Clinic

Andes, David R.; Safdar, Nasia; Baddley, John W.; Alexander, Barbara; Brumble, Lisa; Freifeld, Allison; Hadley, Susan; University of Iowa School of Medicine; Kauffman, Carol; Lyon, G. Marshall; Morrison, Vicki; Patterson, Thomas; Perl, Trish; Walker, Randall; Hess, Tim; Centers for Disease Control and Prevention; and Pappas, Peter G., "The epidemiology and outcomes of invasive Candida infections among organ transplant recipients in the United States: results of the Transplant-Associated Infection Surveillance Network (TRANSNET)" (2016). Public Health Resources. 495.

http://digitalcommons.unl.edu/publichealthresources/495

This Article is brought to you for free and open access by the Public Health Resources at DigitalCommons@University of Nebraska - Lincoln. It has been accepted for inclusion in Public Health Resources by an authorized administrator of DigitalCommons@University of Nebraska - Lincoln. 
See next page for additional authors

Follow this and additional works at: http://digitalcommons.unl.edu/publichealthresources 


\section{Authors}

David R. Andes, Nasia Safdar, John W. Baddley, Barbara Alexander, Lisa Brumble, Allison Freifeld, Susan Hadley, University of Iowa School of Medicine, Carol Kauffman, G. Marshall Lyon, Vicki Morrison, Thomas Patterson, Trish Perl, Randall Walker, Tim Hess, Centers for Disease Control and Prevention, and Peter G. Pappas 


\title{
The epidemiology and outcomes of invasive Candida infections among organ transplant recipients in the United States: results of the Transplant-Associated Infection Surveillance Network (TRANSNET)
}

\author{
David R. Andes $^{1}$ | Nasia Safdar ${ }^{1}$ | John W. Baddley ${ }^{2}$ | Barbara Alexander ${ }^{3}$ | \\ Lisa Brumble $^{4}$ | Allison Freifeld ${ }^{5}$ | Susan Hadley ${ }^{6}$ | Loreen Herwaldt $^{7}$ | \\ Carol Kauffman $^{8}$ | G. Marshall Lyon ${ }^{9}$ | Vicki Morrison ${ }^{10}$ | Thomas Patterson ${ }^{11}$ | \\ Trish Perl $^{12}$ | Randall Walker ${ }^{4}$ | Tim Hess ${ }^{1}$ | Tom Chiller ${ }^{13}$ | Peter G. Pappas ${ }^{2}$ | \\ The TRANSNET Investigators
}

\footnotetext{
${ }^{1}$ Department of Medicine and

Microbiology, University of Wisconsin,

Madison, WI, USA

${ }^{2}$ Department of Medicine, University of Alabama at Birmingham, Birmingham, AL, USA

${ }^{3}$ Department of Medicine, Duke University School of Medicine, Durham, NC, USA

${ }^{4}$ Department of Medicine, Mayo Clinic, Rochester, MN, USA

${ }^{5}$ Department of Medicine, University of Nebraska, Lincoln, NE, USA

${ }^{6}$ Department of Medicine, Tufts University, Boston, MA, USA

${ }^{7}$ Department of Medicine, University of lowa School of Medicine, lowa City, IA, USA

${ }^{8}$ Department of Medicine, Michigan University School of Medicine, Ann Arbor, MI, USA

${ }^{9}$ Emory University, Atlanta, GA, USA

${ }^{10}$ Department of Medicine, University of Minnesota School of Medicine, Minneapolis, MN, USA

${ }^{11}$ Department of Medicine, University of Texas at San Antonio, San Antonio, TX, USA

${ }^{12}$ Department of Medicine, Johns Hopkins University, Baltimore, MD, USA

${ }^{13}$ Centers for Disease Control and

Prevention, Atlanta, GA, USA

Correspondence

David R. Andes, Department of Medicine and Microbiology, University of Wisconsin Madison, Madison, WI, USA.

Email: dra@medicine.wisc.edu
}

\begin{abstract}
Background: Invasive candidiasis (IC) is a common cause of mortality in solid organ transplant recipients (OTRs), but knowledge of epidemiology in this population is limited.

Method: The present analysis describes data from 15 US centers that prospectively identified IC from nearly 17000 OTRs. Analyses were undertaken to determine predictors of infection and mortality.

Results: A total of 639 cases of IC were identified. The most common species was Candida albicans (46.3\%), followed by Candida glabrata (24.4\%) and Candida parapsilosis (8.1\%). In 68 cases $>1$ species was identified. The most common infection site was bloodstream (44\%), followed by intra-abdominal (14\%). The most frequently affected allograft groups were liver (41.1\%) and kidney (35.3\%). All-cause mortality at 90 days was $26.5 \%$ for all species and was highest for Candida tropicalis (44\%) and C. parapsilosis (35.2\%). Non-white race and female gender were more commonly associated with non-albicans species. A high rate of breakthrough IC was seen in patients receiving antifungal prophylaxis (39\%). Factors associated with mortality include organ dysfunction, lung transplant, and treatment with a polyene antifungal. The only modifiable factor identified was choice of antifungal drug class based upon infecting Candida species.
\end{abstract}

Conclusion: These data highlight the common and distinct features of IC in OTRs.

KEYWORDS

Candida, solid organ transplant 


\section{1 | INTRODUCTION}

Advances in transplantation biology, organ procurement, surgical techniques, and immunosuppressive therapy have made organ transplantation an effective option for the management of organ failure, with a 1-year survival $>60 \%-80 \%$. However, infection remains one of the most challenging complications of solid organ transplantation. ${ }^{1-5}$ The most prevalent mycosis is invasive candidiasis (IC) and is associated with considerable mortality. ${ }^{6-13}$ An understanding of the epidemiology and organ transplant type-specific risk factors and outcomes may identify effective prevention and treatment strategies.

The Transplant-Associated Infection Surveillance Network (TRANSNET) was established in 2001 as a prospective surveillance group for the purpose of understanding the burden of invasive fungal infections, and to better define patients at risk and outcome of these infections. ${ }^{14,15}$ The group included 15 geographically diverse transplant centers in the United States that provided infection surveillance data for invasive fungal infections in solid organ transplant recipients (OTRs). The emphasis of this report is to examine the epidemiology and outcomes of IC.

\section{2 | METHODS}

\section{1 | Study population}

Fifteen TRANSNET sites performed transplantation and provided prospective surveillance on these patients. The period of IC infection surveillance was 2001 through 2006, and included all OTRs who developed an IC infection during this period. Information collected on patients included demographics (age, gender, race/ethnicity) and type of transplant. Follow-up information for the cohort was gathered to obtain date of last follow-up and patient status (alive or dead).

\subsection{Definitions and case identification}

Only proven and probable IC infections as defined by the EORTC/MSG criteria $^{16,17}$ were included (see definitions in supplemental Data S1). Lower urinary tract infection and mucosal infections were excluded. Cases were reviewed to determine individual case validity by a Data Review Committee. IC was identified prospectively among this population by establishing monthly patient logs of transplant recipients, reviewing pertinent culture data and histopathology, as well as through the routine contact with transplant physicians and coordinators. Case information included infection site, culture data, method of diagnosis, date and type of transplant, history of rejection, comorbid conditions, cytomegalovirus infection (based on tissue histopathology or viremia), recent immunosuppressive and antifungal treatment data, and patient status at least 3 months after initial diagnosis of IC infection.

\section{3 | Microbiologic methods}

Available cultures and histopathological specimens were processed at the participating hospitals. Species identification was performed using routine methods at the participants' affiliated laboratories. Available fungal isolates were forwarded to the Centers for Disease Control Mycotic Diseases Branch for confirmation of identification.

\section{4 | Data analysis}

Univariate analyses to assess the relationship between variables and survival were performed by tabulating these measures in the survivor and non-survivor cohorts. The $x^{2}$ test or the Fisher exact test was used to assess statistical significance for categorical variables and the Wilcoxon rank-sum test was used for continuous variables. Multivariable analyses of factors associated with mortality were performed using stepwise multiple logistic regression via generalized estimating equations. We chose to model the correlation of the repeated measures on some of the individuals with a compound symmetry covariance structure. The criterion for entry into the model was significant at $\alpha=.20$, whereas the criterion for remaining in the model was significant at $a=.05$. Odds ratios (ORs) and corresponding $95 \%$ confidence intervals (Cls) were calculated. A multiple logistic regression model containing the best predictor variables obtained from the stepwise analysis was then run using all available data in order to obtain more robust estimates of the ORs, $95 \% \mathrm{Cls}$, and $\mathrm{P}$-values. Once final models were achieved through the stepwise process, a potential interaction between prednisone use and rejection was evaluated by incorporating an interaction term into the final model.

A time-to-death analysis was also performed. First, a univariate analysis comparing transplant type, and another comparing Candida species were conducted via Kaplan-Meier estimation and the log-rank test. To validate the above logistic regression results, multivariate analyses were run using Cox regression incorporating the final model terms found in logistic models. All statistical tests were 2-tailed and were performed using a $5 \%$ significance level $(a=.05)$. Statistical analyses were performed using the R statistical computing environment, version 2.11 .

\section{3 | RESULTS}

\section{1 | Epidemiology of IC among OTRs}

A total of 639 cases of IC (533 proven and 106 probable) occurred in 594 OTRs from among nearly 17000 patients under surveillance in the study period. The demographic characteristics, transplantation type, and survival in OTRs with IC overall, by transplant type, and Candida species, are presented in Table 1. The rank order of most frequently encountered species was Candida albicans (46.3\%), followed by Candida glabrata (24.4\%), and Candida parapsilosis (8.1\%). In 68 cases $>1$ Candida species was involved in IC. The most common site of IC was bloodstream in $44 \%$ of cases, followed by intra-abdominal infection (14\%). Among the 635 OTRs with IC, infection was observed most commonly in liver $(261,41.1 \%)$, followed by kidney $(224,35.3 \%)$, kidney-pancreas $(58,9.1 \%)$, and lung $(55,8.7 \%$ ) (4 cases were missing organ type classification). The median time to onset for IC was 80 days post transplantation (interquartile range [IQR] 14-545 days). In total, 205 infections were diagnosed early post transplant (within 


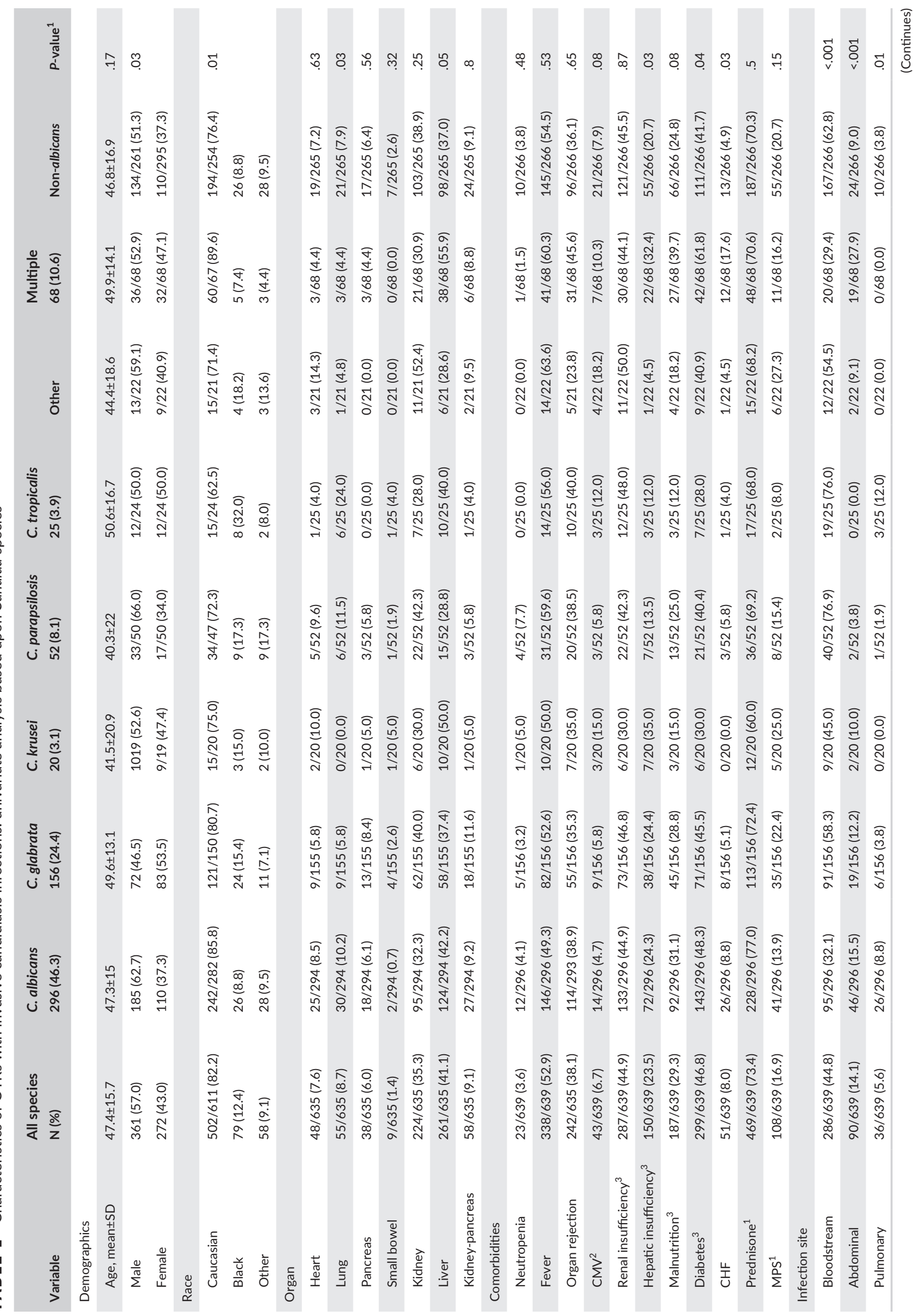




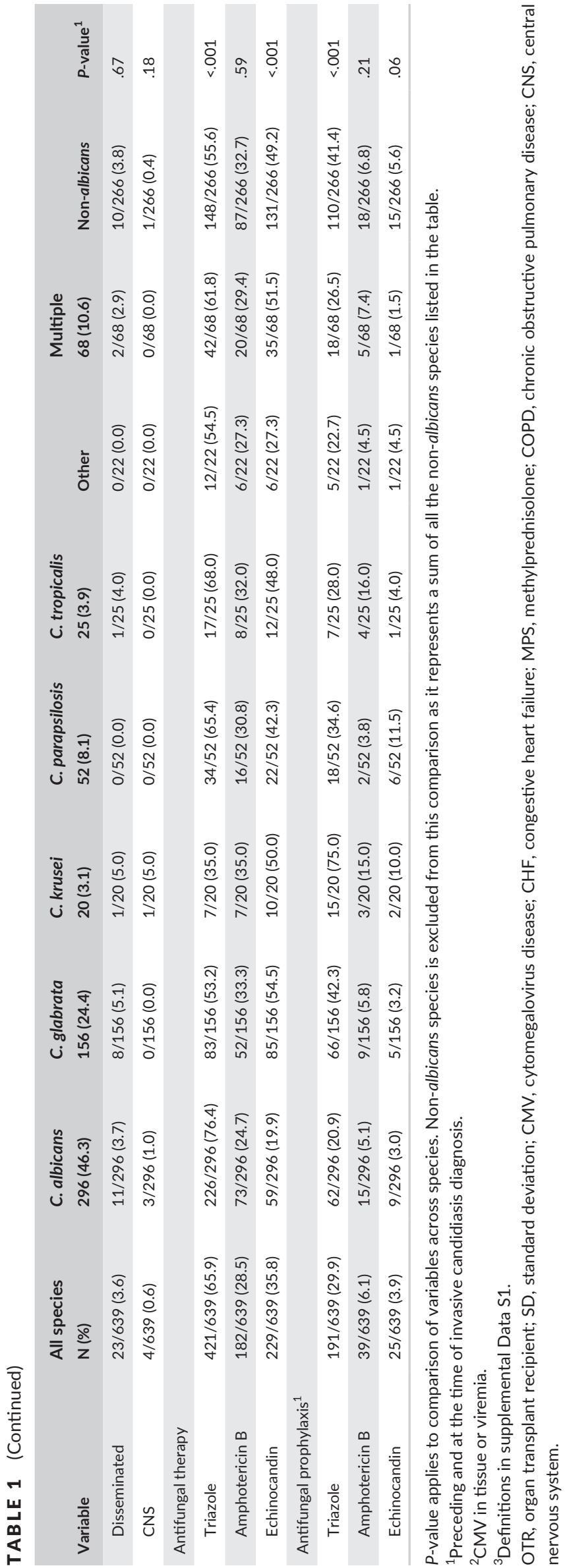

30 days) and 411 were diagnosed late. The mean patient age was 47.4 years and the majority of patients were Caucasian (82.2\%). Several comorbidities were common in cases, including renal (287, $44.9 \%$ ) and hepatic (150, 23.5\%) insufficiency, malnutrition (29.3\%), and diabetes $(299,46.8 \%)$. In addition, allograft rejection was present in $38 \%$ (242) of cases. Patients often received antifungal prophylaxis (nearly $40 \%$ ) at the time of the diagnosis of IC, most with a triazole (fluconazole most frequent; triazole $29.9 \%$, amphotericin B [AmB] formulation $6.1 \%$, echinocandin 3.9\%). For treatment of IC, almost $66 \%$ of patients received a triazole, compared with an AmB formulation (28\%) or an echinocandin (36\%).

\subsection{Characteristics of IC among Candida species}

Survival by Candida species varied as shown in Figure 1. The 90-day mortality by species was $22.6 \%$ for C. albicans, $27.7 \%$ for C. glabrata, $31.5 \%$ for Candida krusei, 35.2\% for C. parapsilosis, and highest for Candida tropicalis (44\%). Epidemiological features in patients with C. albicans $(n=296)$ were contrasted with those who had infection with the second most common species, C. glabrata $(n=156)$. Logistic regression identified both female gender and black race as independent demographic predictors of invasive C. glabrata infection (Table 2). Triazole antifungal use prior to infection was linked to C. glabrata infection. ${ }^{18-20}$ The patient age associated with C. glabrata in this cohort was 49 years. ${ }^{21-24}$ An additional treatment variable associated with C. glabrata infection was use of methyprednisolone (MPS).

We also compared patients with C. albicans $(n=296)$ to those with the aggregate non-albicans species population $(n=258)$. Independent risk factors for IC caused by non-albicans species were similar to those for C. glabrata alone and included black race, female gender, triazole antifungal prophylaxis, kidney transplant over other types of organ transplant, and MPS use. Distinct risk factors associated with C. parapsilosis included younger age (40.3 years, IQR 28.0-58.7). In addition, antifungal prophylaxis with an echinocandin drug was more common in the patients with $C$. parapsilosis breakthrough infections. Among the non-albicans species, late disease onset (>90 days) was also most common for $C$. parapsilosis infection.

\section{3 | Characteristics of IC among transplant organ types}

In total, 48 heart, 55 lung, 38 pancreas, 224 kidney, 261 liver, and 58 kidney-pancreas OTRs were diagnosed with IC. The aggregate mortality associated with IC was $26.5 \%$, but was greatest in the heart, lung, and liver transplant cohorts (heart $25.5 \%$, lung $36.4 \%$, liver $30.9 \%$, pancreas $13.2 \%$, kidney $22.3 \%$, kidney-pancreas $15.5 \%$ ). Allograft rejection was common in the aggregate IC population, but was most common in heart transplant recipients (52.1\% vs [32.4\%-41.4\%]). Use of MPS was also more common in the heart transplant group (33.3\% vs [13.8\%-18.2\%]).

Bloodstream infection was the most common manifestation across the transplant organ types. Intra-abdominal infection was the next most frequent infection site and was associated with allografts below 
FIGURE 1 Kaplan-Meier probability of survival in solid organ transplant (SOT) recipients according to Candida species

TABLE 2 Multivariate analysis of risk factors for infection with select Candida species

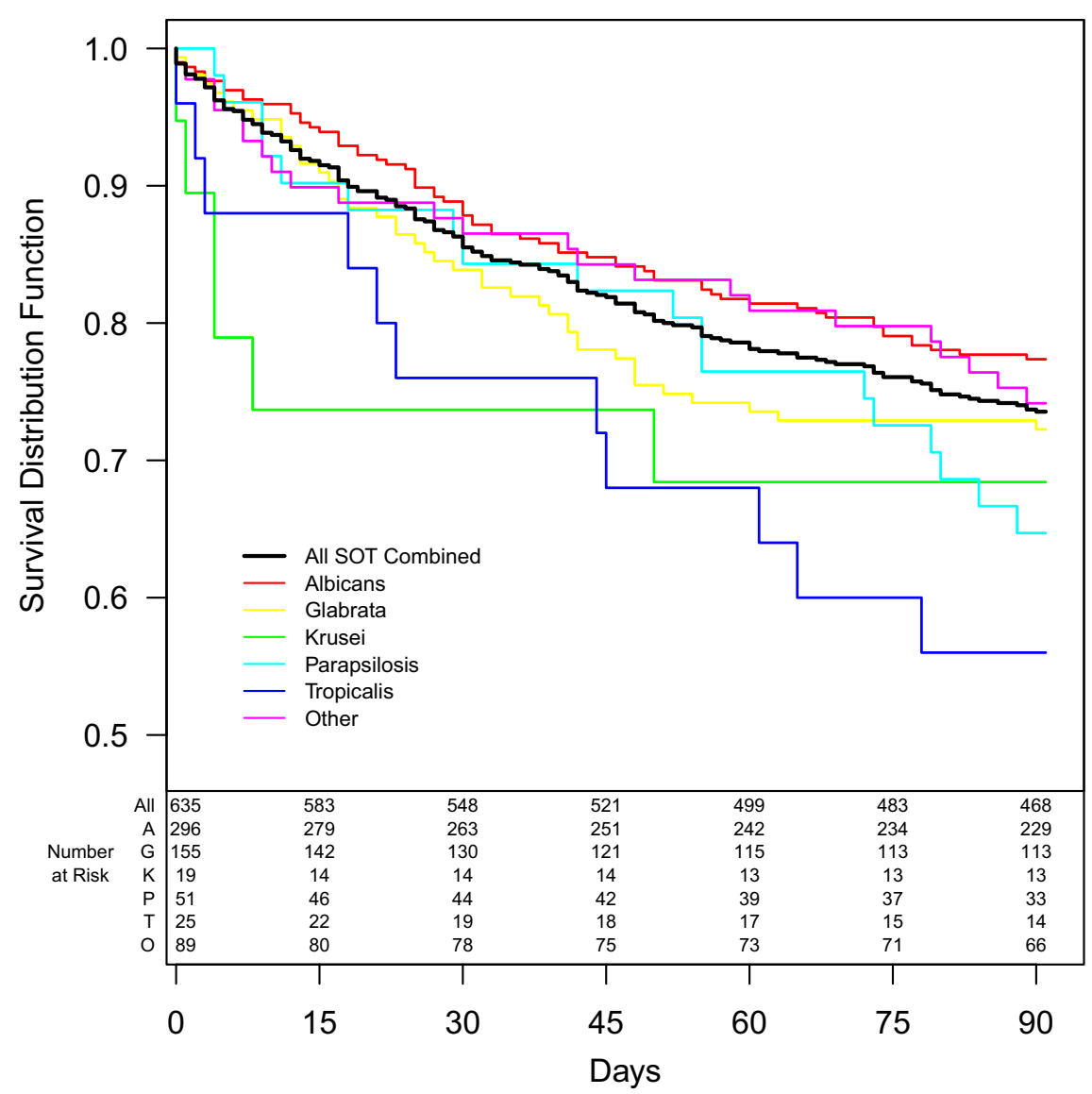

\begin{tabular}{|lllll|}
\hline Variable & Odds ratio & Lower & Upper & P-value \\
\hline $\begin{array}{l}\text { C. albicans vs non-albicans Candida } \\
\text { Black }\end{array}$ & 0.59 & 0.35 & 0.98 & .040 \\
\hline Female & 0.65 & 0.44 & 0.96 & .032 \\
\hline Methyprednisolone & 0.57 & 0.33 & 0.97 & .039 \\
\hline Pulmonary site & 3.22 & 1.26 & 8.24 & .015 \\
\hline CHF & 2.14 & 0.92 & 5.00 & .078 \\
\hline Kidney & 0.59 & 0.39 & 0.90 & .015 \\
\hline Pancreatitis disease & 2.44 & 1.02 & 5.81 & .045 \\
\hline Triazole therapy & 0.37 & 0.24 & 0.57 & $<.001$ \\
\hline C. albicans vs C. glabrata & & & & \\
\hline Black & 0.57 & 0.31 & 1.03 & .063 \\
\hline Female & 0.46 & 0.29 & 0.72 & .001 \\
\hline Age & 0.98 & 0.97 & 1.00 & .028 \\
\hline Methyprednisolone & 0.42 & 0.24 & 0.74 & .003 \\
\hline Triazole prophylaxis & 0.39 & 0.24 & 0.62 & $<.001$ \\
\hline Candida parapsilosis vs non-parapsilosis Candida & & & \\
\hline Age & 0.98 & 0.96 & 0.99 & .011 \\
\hline Early disease & 0.43 & 0.19 & 0.95 & .037 \\
\hline Echinocandin therapy & 4.06 & 1.47 & 11.18 & .007 \\
\hline \hline
\end{tabular}

CHF, congestive heart failure. 
the diaphragm (pancreas 26.3\%, liver 20.7\%, kidney-pancreas 19\%). Antifungal prophylaxis was common among all OTRs with IC (39\%); however, this practice was most common for the heart and lung allograft recipients (heart $64.8 \%$, lung $70.9 \%$ vs pancreas $28.9 \%$, kidney $29.9 \%$, liver $44.8 \%$, and kidney-pancreas $51.7 \%$ ). Among patients who developed IC, antifungal prophylaxis with a triazole was most commonly administered to kidney-pancreas transplant (26/58 44.8\%) and lung transplant recipients (24/55 43.6\%). AmB and echinocandin prophylaxis were much less common in all OTRs. Use of these agents was observed predominantly in the liver transplant cohort (amphotericin $33 / 26112.6 \%$ and echinocandin 14/261 5.4\%).

Triazoles were the most common antifungal drugs used for treatment of IC. This treatment was particularly frequent in pancreas (28/38; 73.7\%) and kidney transplant recipients (158/224; 70.5\%). Additional characteristics in the different transplant types are shown in Table S1.

\subsection{Predictors of mortality in patients with IC}

Ninety-day mortality for all patients was 168/635 (26.5\%). KaplanMeier estimate of 30 -day survival was $85.5 \%$. Survival was statistically different among Candida species (Figure 1). The mortality for non-albicans group was higher than for C. albicans (non-albicans [80/255] 31.4\% vs C. albicans [67/296] 22.6\%, $P=.02$ ). Much of this difference was driven by C. glabrata. However, mortality associated with C. parapsilosis and C. tropicalis infection was also high (35.2\% and $44 \%$ respectively). Independent predictors of mortality in OTRs with IC across all Candida species included renal impairment, congestive heart failure, lung transplant, and treatment with an AmB formulation (Table 3). Prednisone use and IC in the early transplant period (30 days) were associated with reduced risk of mortality.

We performed several subgroup analyses to explore unique outcome factors based on Candida species, organ transplant type, and infection site (Table 4). The majority of elements correlating with outcome were similar among the organism, host, and disease state groups. Organ dysfunction, infection dissemination, and allograft rejection were shared features among those patients who died. A unique association among the subgroups included the relative protection for patients receiving echinocandins in the setting of $C$. glabrata infection (OR 0.45, 95\% Cl 0.17-0.97). Conversely, a trend was seen toward reduced efficacy with this antifungal drug class for C. parapsilosis infection (61.1\% in those that died vs $30.3 \%$ in survivors, $P=.03$ ). Among the renal transplant cohort, the use of $\mathrm{AmB}$ was linked to poor outcome ( $42 \%$ in those who died vs other $21.8 \%$ in survivors, $P<.001)$.

\section{4 | DISCUSSION}

Infection with Candida species was the most common invasive fungal infection among the TRANSNET solid organ transplant population. ${ }^{14}$ The present report included surveillance of $>15 \%$ of organ transplants occurring in the US during the study period, and is among the largest prospective investigations reporting the epidemiology and outcomes of IC in solid OTRs. The results document the importance of IC for this growing patient population. A common theme includes identification of a high prevalence of comorbidities in this IC population, underscoring the complexity of the patients with IC. Almost $50 \%$ of OTRs had renal insufficiency, one-fourth had hepatic dysfunction, nearly $50 \%$ had diabetes, and $30 \%$ had malnutrition. Nearly $40 \%$ experienced episodes of rejection, which may have contributed to the prevalence of organ dysfunction either caused by rejection or anti-rejection therapy. Furthermore, a large percentage of patients had received antifungal prophylaxis prior to development of IC.

Against this backdrop, we found that, similar to other epidemiologic studies of IC, C. albicans remained the most frequent pathogen. However, $>10 \%$ of cases included infection with 2 or more Candida species. The frequency in the present study is more than twice that previously reported..$^{21,25-28}$ Similar to prior reports, this epidemiologic feature did not impact outcome in this cohort. Over the last 2 decades, the proportion of non-albicans Candida species causing IC has steadily increased. ${ }^{9,26,29-33}$ The second most common pathogen in the present study was C. glabrata. ${ }^{34-36}$ The relevance of this increase in non-albicans infections relates to potential for reduced treatment efficacy with certain antifungals owing to differences in susceptibility, in particular, the reduced susceptibility of $C$. glabrata and C. parapsilosis to triazole and echinocandin antifungal drugs respectively. ${ }^{37-40}$ Antifungal susceptibility testing of available isolates demonstrated elevated minimum inhibitory concentrations for these species and drug combinations. ${ }^{40}$ Interestingly, outcome for patients infected with non-albicans species in this transplant cohort was worse than for those with disease caused by C. albicans.

It is notable that we found prophylactic use of drugs from the triazole and echinocandin classes was common for C. glabrata and C. parapsilosis infections and was statistically associated with poorer outcome for these 2 species. The apparent superiority of the echinocandin class for treatment of IC, including infection caused by C. glabrata, has been observed in recent analysis. ${ }^{41}$ Reduced efficacy for this class against less susceptible species, such as C. parapsilosis, has not been evident in clinical trials. ${ }^{38,42,43}$ It is possible that the advanced degree of immunosuppression in this cohort, as suggested by the high rate of both multiorgan failure and allograft rejection, raised the therapeutic hurdle for this pathogen, which is traditionally considered among the least virulent. Indeed, the mortality rate in the transplant population infected with C. parapsilosis was unusually high compared to previous reports. ${ }^{44,45}$ However, the relatively small number of patients with C. parapsilosis in this series precludes drawing firm therapeutic conclusions.

Another unique observation is the relatively young age of patients with C. glabrata infections (<50 years). Other large surveillance studies have reported increased $C$. glabrata risk beyond the fifth decade. ${ }^{20,46,47}$ This finding may be in part a result of a relatively low percentage of transplant recipients above the fifth decade in this cohort $(50.2 \%$ age $>50$ at time of transplant). Two additional unique C. glabrata risk factors of note in the current investigation include the relevance of female gender and black race. A similar race observation has been described for cryptococcal infections in the setting of organ transplantation. ${ }^{48}$ However, the mechanistic basis for this epidemiologic finding remains unclear. We also observed a correlation between the use of 
TABLE 3 Multivariate analysis of risk factors for mortality in OTRs with invasive candidiasis

\begin{tabular}{|c|c|c|c|c|}
\hline Variable & $\begin{array}{l}\text { Odds } \\
\text { ratio }\end{array}$ & Lower & Upper & $P$-value \\
\hline \multicolumn{5}{|l|}{ Candida species subgroup } \\
\hline \multicolumn{5}{|l|}{ All species } \\
\hline Liver transplant & 1.63 & 0.96 & 2.76 & .071 \\
\hline Renal insufficiency & 2.31 & 1.46 & 3.66 & $<.001$ \\
\hline Hepatic insufficiency & 1.68 & 0.97 & 2.91 & .066 \\
\hline $\mathrm{CHF}$ & 3.54 & 1.61 & 7.81 & .002 \\
\hline Pulmonary site & 2.88 & 1.35 & 6.16 & .006 \\
\hline Prednisone & 0.39 & 0.25 & 0.63 & $<.001$ \\
\hline Amphotericin B & 1.99 & 1.24 & 3.2 & .004 \\
\hline Early disease & 0.51 & 0.3 & 0.84 & .009 \\
\hline \multicolumn{5}{|l|}{ C. albicans } \\
\hline Heart transplant & 0.13 & 0.03 & 0.55 & .006 \\
\hline Renal insufficiency & 3.77 & 1.82 & 7.8 & $<.001$ \\
\hline $\mathrm{CHF}$ & 3.49 & 1.2 & 10.11 & .022 \\
\hline Pulmonary site & 2.88 & 0.86 & 9.66 & .088 \\
\hline Disseminated site & 8.66 & 1.74 & 43.01 & .008 \\
\hline Prednisone & 0.37 & 0.17 & 0.8 & .012 \\
\hline Methyprednisolone & 2.61 & 0.98 & 6.93 & .054 \\
\hline Amphotericin B & 2.85 & 1.31 & 6.22 & .009 \\
\hline Echinocandin & 3.25 & 1.4 & 7.58 & .006 \\
\hline Early disease & 0.36 & 0.15 & 0.85 & .021 \\
\hline \multicolumn{5}{|l|}{ C. glabrata } \\
\hline Age & 1.05 & 1.02 & 1.09 & .005 \\
\hline Pancreas transplant & 9.84 & 1.46 & 66.26 & .019 \\
\hline $\mathrm{CHF}$ & 25.06 & 2.71 & 232.13 & .005 \\
\hline Pulmonary site & 5.17 & 0.68 & 39.49 & .113 \\
\hline Prednisone & 0.45 & 0.18 & 1.15 & .094 \\
\hline Echinocandin & 0.4 & 0.17 & 0.97 & .042 \\
\hline \multicolumn{5}{|l|}{ Non-albicans Candida } \\
\hline Heart & 3.86 & 1.14 & 13.05 & .03 \\
\hline Hepatic insufficiency & 3.25 & 1.6 & 6.58 & .001 \\
\hline $\mathrm{CHF}$ & 9.02 & 1.67 & 48.57 & .011 \\
\hline Pulmonary site & 5.01 & 1.76 & 14.28 & .003 \\
\hline Prednisone & 0.48 & 0.25 & 0.93 & .029 \\
\hline Early disease & 0.54 & 0.27 & 1.09 & .084 \\
\hline \multicolumn{5}{|l|}{ Transplant organ subgroups } \\
\hline \multicolumn{5}{|l|}{ Kidney } \\
\hline Hepatic insufficiency & 17.28 & 4.42 & 67.53 & $<.001$ \\
\hline $\mathrm{CHF}$ & 6.29 & 1.89 & 20.93 & .003 \\
\hline Renal insufficiency & 3.63 & 1.39 & 9.44 & .008 \\
\hline Prednisone & 0.2 & 0.07 & 0.57 & .003 \\
\hline Amphotericin & 5.47 & 1.89 & 15.86 & .002 \\
\hline Echinocandin & 5.91 & 0.74 & 47.14 & .093 \\
\hline
\end{tabular}

TABLE 3 (Continued)

\begin{tabular}{|l|cccc|}
\hline $\begin{array}{l}\text { Variable } \\
\text { Odds } \\
\text { Liver }\end{array}$ & Latio & Lower & Upper & P-value \\
\hline Renal insufficiency & 3.12 & 1.54 & 6.32 & .002 \\
\hline CMV & 13.96 & 3.2 & 60.88 & $<.001$ \\
\hline COPD & 0.24 & 0.07 & 0.84 & .026 \\
\hline Disseminated site & 4.3 & 0.92 & 20.06 & .063 \\
\hline Prednisone & 0.27 & 0.13 & 0.6 & .001 \\
\hline Methyprednisolone & 0.28 & 0.09 & 0.89 & .032 \\
\hline Early disease & 0.39 & 0.18 & 0.86 & .02 \\
\hline Candidemia subgroup & & & & \\
\hline Renal insufficiency & 2.24 & 1.39 & 3.61 & $<.001$ \\
\hline CHF & 3.11 & 1.38 & 7.02 & .006 \\
\hline Prednisone & 0.41 & 0.25 & 0.68 & $<.001$ \\
\hline Amphotericin & 2.63 & 1.59 & 4.37 & $<.001$ \\
\hline Echinocandin & 2.01 & 1.22 & 3.3 & .006 \\
\hline Early disease & 0.46 & 0.27 & 0.8 & .006 \\
\hline
\end{tabular}

OTR, organ transplant recipient; CHF, congestive heart failure; CMV, cytomegalovirus; COPD, chronic obstructive pulmonary disease.

MPS and non-albicans Candida infections, especially those caused by C. glabrata. We hypothesize that the use of this higher potency corticosteroid is a marker of organ rejection therapy reflecting enhanced immunosuppression. This observation is congruent with prior studies that link high mortality and $C$. tropicalis infection among patients with hematologic malignancies. ${ }^{49-51}$ We did not identify unique transplant variables to explain this observation.

Candidemia was the commonest microbiologic manifestation of IC in this study. The second most common site was intra-abdominal, and not surprisingly, the majority of the cases occurred in abdominal cavity allografts. ${ }^{52-54}$ Advanced disease, as marked by categorization as disseminated or organ disease other than abdominal was observed in $>10 \%$ of patients. This rate of multi-organ involvement is comparable with reports of IC in the non-transplant population. ${ }^{7,12,52,53}$ The impact of the pulmonary infection site on outcome is intriguing, but the relevance unclear. We speculate this could be an indication of dissemination or simply a high burden of Candida, as suggested in prior colonization studies.

Examination of antifungal choice for prophylaxis and therapy in the current population revealed a use pattern consistent with prior surveys. ${ }^{12,21,55,56}$ Prophylaxis was dominated by the triazole class, predominantly fluconazole. Definitive treatment represented a mixed approach, and included a high percentage of echinocandins and comparatively little use of polyenes, probably owing to the differential risk for nephrotoxicity. Triazole prophylaxis in this cohort was successful in the prevention of IC by C. albicans, as previously reported. ${ }^{56-59}$ However, the rate of breakthrough IC cases in this cohort was striking. Analyses demonstrated that many emergent infections were caused by species with higher minimum inhibitory concentrations to antifungal compounds. ${ }^{42}$ In the setting of triazole prophylaxis, infection with 
TABLE 4 Characteristics of OTRs with invasive candidiasis based upon transplant organ

\begin{tabular}{|c|c|c|c|c|c|c|}
\hline Variable & Heart & Lung & Pancreas & Kidney & Liver & Kidney-pancreas \\
\hline Age, mean $\pm S D$ & $52.8 \pm 19.3$ & $48.2 \pm 15.7$ & $44.5 \pm 7.5$ & $48.1 \pm 12.9$ & $46.9 \pm 17.1$ & $42.6 \pm 9.1$ \\
\hline Female & $13 / 48(27.1)$ & $32 / 54(59.3)$ & $18 / 37(48.6)$ & $110 / 222(49.5)$ & $95 / 259(36.7)$ & $28 / 58(48.3)$ \\
\hline \multicolumn{7}{|l|}{ Race } \\
\hline Black & $3(6.4)$ & 7 (12.7) & $0(0.0)$ & $43(19.2)$ & $23(8.9)$ & 7 (12.1) \\
\hline Other & $5(10.6)$ & $5(9.1)$ & $1(2.6)$ & $14(6.2)$ & 32 (12.4) & $3(5.2)$ \\
\hline \multicolumn{7}{|l|}{ Comorbidities } \\
\hline Neutropenia & $1 / 48(2.1)$ & $1 / 55$ (1.8) & $2 / 38(5.3)$ & $7 / 224(3.1)$ & $12 / 261(4.6)$ & $2 / 58(3.4)$ \\
\hline Renal insufficiency & $33 / 48(68.8)$ & $23 / 55(41.8)$ & $8 / 38(21.1)$ & $106 / 224(47.3)$ & $116 / 261(44.4)$ & $22 / 58$ (37.9) \\
\hline Hepatic insufficiency & $6 / 48(12.5)$ & $2 / 55(3.6)$ & $1 / 38(2.6)$ & $29 / 224$ (12.9) & $111 / 261(42.5)$ & $6 / 58(10.3)$ \\
\hline Malnutrition & 4/48 (8.3) & $10 / 55(18.2)$ & 6/38 (15.8) & $67 / 224(29.9)$ & $95 / 261(36.4)$ & $19 / 58(32.8)$ \\
\hline Diabetes & 28/48 (58.3) & $18 / 55(32.7)$ & $12 / 38(31.6)$ & $108 / 224(48.2)$ & $130 / 261(49.8)$ & $26 / 58(44.8)$ \\
\hline COPD & $3 / 48(6.2)$ & $13 / 55(23.6)$ & $0 / 38(0.0)$ & $16 / 224(7.1)$ & 29/261 (11.1) & $3 / 58(5.2)$ \\
\hline $\mathrm{CHF}$ & 9/48 (18.8) & $3 / 55(5.5)$ & $2 / 38(5.3)$ & $25 / 224(11.2)$ & $12 / 261(4.6)$ & $5 / 58(8.6)$ \\
\hline Autoimmune & $3 / 48(6.2)$ & $6 / 55(10.9)$ & $0 / 38(0.0)$ & $19 / 224(8.5)$ & $15 / 261(5.7)$ & $2 / 58(3.4)$ \\
\hline Pancreatitis & $2 / 48(4.2)$ & $0 / 55(0.0)$ & $2 / 38(5.3)$ & $30 / 224(13.4)$ & $11 / 261(4.2)$ & 11/58 (19.0) \\
\hline HIV/AIDS & $0 / 48(0.0)$ & $0 / 55(0.0)$ & $0 / 38(0.0)$ & $2 / 224(0.9)$ & $0 / 261(0.0)$ & $0 / 58(0.0)$ \\
\hline C. parapsilosis & $4(8.5)$ & $6(10.9)$ & $3(7.9)$ & $22(9.8)$ & $15(5.8)$ & $3(5.2)$ \\
\hline C. tropicalis & $1(2.1)$ & $6(10.9)$ & $0(0.0)$ & $7(3.1)$ & $10(3.9)$ & $1(1.7)$ \\
\hline C. lusitaniae & $1(2.1)$ & $0(0.0)$ & $0(0.0)$ & $3(1.3)$ & $1(0.4)$ & $0(0.0)$ \\
\hline Multiple & $3(6.4)$ & $3(5.5)$ & $3(7.9)$ & $21(9.4)$ & $38(14.7)$ & $6(10.3)$ \\
\hline Other & $1(2.1)$ & $0(0.0)$ & $0(0.0)$ & $3(1.3)$ & $4(1.5)$ & $1(1.7)$ \\
\hline Unspecified & $1(2.1)$ & $1(1.8)$ & $0(0.0)$ & $5(2.2)$ & $1(0.4)$ & $1(1.7)$ \\
\hline \multicolumn{7}{|l|}{ Infection site } \\
\hline Bloodstream & $31 / 48(64.6)$ & $29 / 55(52.7)$ & $12 / 38(31.6)$ & $99 / 224(44.2)$ & $107 / 261(41.0)$ & $15 / 58(25.9)$ \\
\hline Abdominal & $0 / 48(0.0)$ & $0 / 55(00.0)$ & $10 / 38(26.3)$ & $26 / 224$ (11.6) & $54 / 261(20.7)$ & 11/58 (19.0) \\
\hline Pulmonary & 4/48 (8.3) & $17 / 55$ (30.9) & $1 / 38(2.6)$ & $3 / 224(1.3)$ & $9 / 261(3.4)$ & $1 / 58(1.7)$ \\
\hline Disseminated & $3 / 48(6.2)$ & $0 / 55(0.0)$ & $1 / 38(2.6)$ & $9 / 224(4.0)$ & 10/261 (3.8) & $2 / 58(3.4)$ \\
\hline CNS & 0/48 (0.0) & 0/55 (0.0) & 0/38 (0.0) & $3 / 224(1.3)$ & $1 / 261(0.4)$ & 0/58 (0.0) \\
\hline \multicolumn{7}{|l|}{ Antifungal therapy ${ }^{1}$} \\
\hline Triazole & $31 / 48(64.6)$ & $38 / 55(69.1)$ & $28 / 38(73.7)$ & $158 / 224(70.5)$ & $158 / 261(60.5)$ & $39 / 58(67.2)$ \\
\hline Amphotericin & $14 / 48(29.2)$ & $15 / 55(27.3)$ & $9 / 38$ (23.7) & $59 / 224(26.3)$ & $82 / 261(31.4)$ & $17 / 58(29.3)$ \\
\hline Echinocandin & $13 / 48(27.1)$ & $10 / 55(18.2)$ & $14 / 38(36.8)$ & $85 / 224$ (37.9) & $102 / 261$ (39.1) & $24 / 58(41.4)$ \\
\hline
\end{tabular}


TABLE 4 (Continued)

\begin{tabular}{|c|c|c|c|c|c|c|}
\hline Variable & Heart & Lung & Pancreas & Kidney & Liver & Kidney-pancreas \\
\hline \multicolumn{7}{|c|}{ Antifungal prophylaxis } \\
\hline Triazole & $19 / 48(39.6)$ & $24 / 55$ (43.6) & $11 / 38(28.9)$ & $58 / 224(25.9)$ & $70 / 261(26.8)$ & $26 / 58(44.8)$ \\
\hline Amphotericin & $2 / 48(4.2)$ & $12 / 55(21.8)$ & $0 / 38(0.0)$ & $2 / 224(0.9)$ & $33 / 261$ (12.6) & $1 / 58(1.7)$ \\
\hline Echinocandin & $1 / 48(2.1)$ & $3 / 55(5.5)$ & $0 / 38(0.0)$ & $7 / 224(3.1)$ & $14 / 261(5.4)$ & $3 / 58(5.2)$ \\
\hline
\end{tabular}

${ }^{1}$ Includes sequential or combination therapy.

OTR, organ transplant recipient; SD, standard deviation; CMV, cytomegalovirus, COPD, chronic obstructive pulmonary disease; CHF, congestive heart failure; HIV/AIDS, human immunodeficiency virus/acquired immunodeficiency syndrome; MPS, methylprednisolone; CNS, central nervous system.

C. glabrata was common. This observation is congruent with previously reported prophylaxis studies. ${ }^{18}$ Interestingly, we also found an association between echinocandin prophylaxis and infection with $C$. parapsilosis (6/52, 11.5\%), and this finding is consistent with the reduced efficacy described in the setting of definitive therapy described above.

A number of comorbidities were strongly related to poor outcomes. Neutropenia, heart failure, and renal and hepatic dysfunction each conferred a negative impact on outcome. Interestingly, we found a disparate impact for 2 corticosteroid formulations, prednisone and MPS. As noted above, we theorize that use of MPS is a marker of rejection and this likely translates into a risk for poor outcome. Conversely, use of prednisone may suggest stable allograft function and may explain the observed "protective" nature of this therapy. Early disease was also predictive of a favorable outcome. We theorize that this improvement may be a result of earlier diagnosis linked to enhanced vigilance in the early post-transplant period.

The results of this survey both confirm and extend our understanding of the features of IC in solid OTRs. We identified a hierarchy of risk for disease and outcome based on transplant type, underlying disease, and comorbid conditions. We did not identify directly modifiable factors, other than an emphasis on the importance of drug selection for certain Candida species, which is intuitive based upon fairly predictable antifungal drug susceptibility. Current evidence suggests that echinocandins are the optimal empiric antifungal drug choice for IC. $^{43}$ In the current study, this benefit is less clear for infection caused by $C$. parapsilosis, but numbers are small. The absence of other readily identifiable factors under the direct control of clinicians underscores the importance of a high index of suspicion in this complex patient population. In particular, the presence of organ dysfunction and rejection should prompt surveillance for this infectious complication. Furthermore, these observations highlight the need for improved fungal diagnostics and more effective antifungal compounds.

The TRANSNET database is comprehensive, but it has several limitations. Baseline and longitudinal laboratory data were minimal and specific information about drug exposure was incomplete. For example, information regarding antifungal, antiviral, and antibacterial prophylaxis was limited, as were data pertaining to vascular catheter management, immunosuppressive regimens, and institution-specific practices and protocols. It is possible that information regarding catheters may have shed light on the relatively high mortality linked to C. parapsilosis infection. Moreover, the dataset does not include data on disease severity and transplant incompatibility characteristics.
These important covariates should be explored more fully in future studies. In addition, the period of data collection ended in 2006, thus practice changes may have occurred that limit extrapolation of findings. For example, echinocandins have emerged as the preferred therapy for treatment of IC over AmB and triazoles. Immunosuppressive and antifungal prophylaxis regimens also continue to evolve. Finally, this analysis is based on all-cause mortality, as attribution to IC as a contributing cause to mortality is difficult, and generally reflects investigator opinion. Despite these limitations, this analysis from a large and comprehensive database provides important insights into factors that are associated with mortality among OTRs who develop IC, and these data may be useful in developing strategies for prevention and treatment of this important post-transplantation complication.

\section{REFERENCES}

1. Russell DL, Flood A, Zaroda TE, et al. Outcomes of colonization with MRSA and VRE among liver transplant candidates and recipients. Am J Transplant. 2008;8:1737-1743.

2. Moreno A, Cervera C, Gavalda J, et al. Bloodstream infections among transplant recipients: results of a nationwide surveillance in Spain. Am J Transplant. 2007;7:2579-2586.

3. Al-Hasan MN, Razonable RR, Eckel-Passow JE, Baddour LM. Incidence rate and outcome of Gram-negative bloodstream infection in solid organ transplant recipients. Am J Transplant. 2009;9: 835-843.

4. Aberg F, Makisalo H, Hockerstedt $\mathrm{K}$, Isoniemi H. Infectious complications more than 1 year after liver transplantation: a 3-decade nationwide experience. Am J Transplant. 2011;11:287-295.

5. Lumbreras C, Fernandez I, Velosa J, Munn S, Sterioff S, Paya CV. Infectious complications following pancreatic transplantation: incidence, microbiological and clinical characteristics, and outcome. Clin Infect Dis. 1995;20:514-520.

6. Pappas PG, Andes D, Schuster M, et al. Invasive fungal infections in low-risk liver transplant recipients: a multi-center prospective observational study. Am J Transplant. 2006;6:386-391.

7. Paya CV. Fungal infections in solid-organ transplantation. Clin Infect Dis. 1993;16:677-688.

8. Fortun J, Lopez-San Roman A, Velasco JJ, et al. Selection of Candida glabrata strains with reduced susceptibility to azoles in four liver transplant patients with invasive candidiasis. Eur J Clin Microbiol Infect Dis. 1997;16:314-318.

9. Pfaller MA, Diekema DJ. Epidemiology of invasive candidiasis: a persistent public health problem. Clin Microbiol Rev. 2007;20:133-163.

10. Morgan J, Meltzer MI, Plikaytis BD, et al. Excess mortality, hospital stay, and cost due to candidemia: a case-control study using data from population-based candidemia surveillance. Infect Control Hosp Epidemiol. 2005;26:540-547. 
11. Zaoutis TE, Argon J, Chu J, Berlin JA, Walsh TJ, Feudtner C. The epidemiology and attributable outcomes of candidemia in adults and children hospitalized in the United States: a propensity analysis. Clin Infect Dis. 2005;41:1232-1239.

12. Horn DL, Neofytos D, Anaissie EJ, et al. Epidemiology and outcomes of candidemia in 2019 patients: data from the prospective antifungal therapy alliance registry. Clin Infect Dis. 2009;48:1695-1703.

13. Wenzel RP. Nosocomial candidemia: risk factors and attributable mortality. Clin Infect Dis. 1995;20:1531-1534.

14. Pappas PG, Alexander BD, Andes DR, et al. Invasive fungal infections among organ transplant recipients: results of the TransplantAssociated Infection Surveillance Network (TRANSNET). Clin Infect Dis. 2010;50:1101-1111.

15. Kontoyiannis DP, Marr KA, Park BJ, et al. Prospective surveillance for invasive fungal infections in hematopoietic stem cell transplant recipients, 2001-2006: overview of the Transplant-Associated Infection Surveillance Network (TRANSNET) Database. Clin Infect Dis. 2010;50:1091-1100.

16. Ascioglu S, Rex JH, de Pauw B, et al. Defining opportunistic invasive fungal infections in immunocompromised patients with cancer and hematopoietic stem cell transplants: an international consensus. Clin Infect Dis. 2002;34:7-14.

17. De Pauw B, Walsh TJ, Donnelly JP, et al. Revised definitions of invasive fungal disease from the European Organization for Research and Treatment of Cancer/Invasive Fungal Infections Cooperative Group and the National Institute of Allergy and Infectious Diseases Mycoses Study Group (EORTC/MSG) Consensus Group. Clin Infect Dis. 2008;46:1813-1821.

18. Wingard JR, Merz WG, Rinaldi MG, Miller CB, Karp JE, Saral R. Association of Torulopsis glabrata infections with fluconazole prophylaxis in neutropenic bone marrow transplant patients. Antimicrob Agents Chemother. 1993;37:1847-1849.

19. Uzun O, Ascioglu S, Anaissie EJ, Rex JH. Risk factors and predictors of outcome in patients with cancer and breakthrough candidemia. Clin Infect Dis. 2001;32:1713-1717.

20. Pfaller MA, Messer SA, Hollis RJ, et al. Variation in susceptibility of bloodstream isolates of Candida glabrata to fluconazole according to patient age and geographic location in the United States in 2001 to 2007. J Clin Microbiol. 2009;47:3185-3190.

21. Pfaller MA, Andes DR, Diekema DJ, et al. Epidemiology and outcomes of invasive candidiasis due to non-albicans species of Candida in 2,496 patients: data from the Prospective Antifungal Therapy (PATH) registry 2004-2008. PLoS One. 2014;9:e101510.

22. Klevay MJ, Ernst EJ, Hollanbaugh JL, Miller JG, Pfaller MA, Diekema DJ. Therapy and outcome of Candida glabrata versus Candida albicans bloodstream infection. Diagnost Microbiol Infect Dis. 2008;60:273-277.

23. Pfaller M, Neofytos D, Diekema D, et al. Epidemiology and outcomes of candidemia in 3648 patients: data from the Prospective Antifungal Therapy (PATH Alliance(R)) registry, 2004-2008. Diagnost Microbiol Infect Dis. 2012;74:323-331.

24. Fidel PL Jr, Vazquez JA, Sobel JD. Candida glabrata: review of epidemiology, pathogenesis, and clinical disease with comparison to C. albicans. Clin Microbiol Rev. 1999;12:80-96.

25. Pappas PG, Rex JH, Lee J, et al. A prospective observational study of candidemia: epidemiology, therapy, and influences on mortality in hospitalized adult and pediatric patients. Clin Infect Dis. 2003;37:634-643.

26. Kim SH, Yoon YK, Kim MJ, Sohn JW. Risk factors for and clinical implications of mixed Candida/bacterial bloodstream infections. Clin Microbiol Infect. 2013;19:62-68.

27. Pulimood S, Ganesan L, Alangaden G, Chandrasekar P. Polymicrobial candidemia. Diagn Microbiol Infect Dis. 2002;44:353-357.

28. Klotz SA, Chasin BS, Powell B, Gaur NK, Lipke PN. Polymicrobial bloodstream infections involving Candida species: analysis of patients and review of the literature. Diagn Microbiol Infect Dis. 2007;59:401-406.
29. Cleveland AA, Farley MM, Harrison LH, et al. Changes in incidence and antifungal drug resistance in candidemia: results from populationbased laboratory surveillance in Atlanta and Baltimore, 2008-2011. Clin Infect Dis. 2012;55:1352-1361.

30. Falagas ME, Roussos N, Vardakas KZ. Relative frequency of albicans and the various non-albicans Candida spp among candidemia isolates from inpatients in various parts of the world: a systematic review. Int J Infect Dis. 2010;14:e954-e966.

31. Nguyen MH, Peacock JE Jr, Morris AJ, et al. The changing face of candidemia: emergence of non-Candida albicans species and antifungal resistance. Am J Med. 1996;100:617-623.

32. Hachem R, Hanna H, Kontoyiannis D, Jiang Y, Raad I. The changing epidemiology of invasive candidiasis: Candida glabrata and Candida krusei as the leading causes of candidemia in hematologic malignancy. Cancer. 2008;112:2493-2499.

33. Trick WE, Fridkin SK, Edwards JR, Hajjeh RA, Gaynes RP, National Nosocomial Infections Surveillance System Hospitals. Secular trend of hospital-acquired candidemia among intensive care unit patients in the United States during 1989-1999. Clin Infect Dis. 2002;35:627-630.

34. Almirante B, Rodriguez D, Park BJ, et al. Epidemiology and predictors of mortality in cases of Candida bloodstream infection: results from population-based surveillance, barcelona, Spain, from 2002 to 2003. J Clin Microbiol. 2005;43:1829-1835.

35. Pfaller MA, Jones RN, Doern GV, Sader HS, Hollis RJ, Messer SA International surveillance of bloodstream infections due to Candida species: frequency of occurrence and antifungal susceptibilities of isolates collected in 1997 in the United States, Canada, and South America for the SENTRY Program. The SENTRY Participant Group. $J$ Clin Microbiol. 1998;36:1886-1889.

36. Pfaller MA, Jones RN, Doern GV, et al. Bloodstream infections due to Candida species: SENTRY antimicrobial surveillance program in North America and Latin America, 1997-1998. Antimicrob Agents Chemother. 2000;44:747-751.

37. Morrison VA. Echinocandin antifungals: review and update. Expert Rev Anti Infect Ther. 2006;4:325-342.

38. Lortholary O, Desnos-Ollivier M, Sitbon K, et al. Recent exposure to caspofungin or fluconazole influences the epidemiology of candidemia: a prospective multicenter study involving 2,441 patients. Antimicrob Agents Chemother. 2011;55:532-538.

39. Pfaller M, Boyken L, Hollis R, et al. Use of epidemiological cutoff values to examine 9-year trends in susceptibility of Candida species to anidulafungin, caspofungin, and micafungin. J Clin Microbiol. 2011;49:624-629.

40. Lockhart SR, Wagner D, Iqbal N, et al. Comparison of in vitro susceptibility characteristics of Candida species from cases of invasive candidiasis in solid organ and stem cell transplant recipients: Transplant-Associated Infections Surveillance Network (TRANSNET), 2001 to 2006. J Clin Microbiol. 2011;49:2404-2410.

41. Andes DR, Safdar N, Baddley JW, et al. Impact of treatment strategy on outcomes in patients with candidemia and other forms of invasive candidiasis: a patient-level quantitative review of randomized trials. Clin Infect Dis. 2012;54:1110-1122.

42. Forrest GN, Weekes E, Johnson JK. Increasing incidence of Candida parapsilosis candidemia with caspofungin usage. J Infect. 2008;56:126-129.

43. Reboli AC. Editorial commentary: Is the debate about treatment of Candida parapsilosis complex infections with echinocandins much ado about nothing? Clin Infect Dis. 2014;58:1422-1423.

44. Weems JJ Jr. Candida parapsilosis: epidemiology, pathogenicity, clinical manifestations, and antimicrobial susceptibility. Clin Infect Dis. 1992;14:756-766.

45. Trofa D, Gacser A, Nosanchuk JD. Candida parapsilosis, an emerging fungal pathogen. Clin Microbiol Rev. 2008;21:606-625.

46. Pfaller MA, Messer SA, Boyken L, Tendolkar S, Hollis RJ, Diekema DJ. Variation in susceptibility of bloodstream isolates of Candida glabrata to fluconazole according to patient age and geographic location. J Clin Microbiol. 2003;41:2176-2179. 
47. Pfaller MA, Diekema DJ, Gibbs DL, et al. Geographic variation in the frequency of isolation and fluconazole and voriconazole susceptibilities of Candida glabrata: an assessment from the ARTEMIS DISK Global Antifungal Surveillance Program. Diagn Microbiol Infect Dis. 2010;67:162-171.

48. Boehme AK, McGwin G, Andes DR, et al. Race and invasive fungal infection in solid organ transplant recipients. Ethn Dis. 2014;24:382-385.

49. Weinberger M, Leibovici L, Perez S, et al. Characteristics of candidaemia with Candida-albicans compared with non-albicans Candida species and predictors of mortality. J Hosp Infect. 2005;61:146-154.

50. Leung AY, Chim CS, Ho PL, et al. Candida tropicalis fungaemia in adult patients with haematological malignancies: clinical features and risk factors. J Hosp Infect. 2002;50:316-319.

51. Husain S, Tollemar J, Dominguez EA, et al. Changes in the spectrum and risk factors for invasive candidiasis in liver transplant recipients: prospective, multicenter, case-controlled study. Transplantation. 2003;75:2023-2029.

52. Kusne S, Dummer JS, Singh N, et al. Infections after liver transplantation. An analysis of 101 consecutive cases. Medicine. 1988;67:132-143.

53. Patel R, Portela D, Badley AD, et al. Risk factors of invasive Candida and non-Candida fungal infections after liver transplantation. Transplantation. 1996;62:926-934.

54. Neofytos D, Fishman JA, Horn D, et al. Epidemiology and outcome of invasive fungal infections in solid organ transplant recipients. Transpl Infect Dis. 2010;12:220-229.

55. Cornely OA, Gachot B, Akan H, et al.; EORTC Infectious Diseases Group. Epidemiology and outcome of fungemia in a cancer cohort of the Infectious Diseases Group (IDG) of the European Organization for Research and Treatment of Cancer (EORTC 65031). Clin Infect Dis. 2015;61:324-331.
56. Pappas PG, Kauffman CA, Andes D, et al. Clinical practice guidelines for the management of candidiasis: 2009 update by the Infectious Diseases Society of America. Clin Infect Dis. 2009;48:503-535.

57. Winston DJ, Limaye AP, Pelletier S, et al. Randomized, double-blind trial of anidulafungin versus fluconazole for prophylaxis of invasive fungal infections in high-risk liver transplant recipients. Am J Transplant. 2014;14:2758-2764.

58. Marr KA, Seidel K, Slavin MA, et al. Prolonged fluconazole prophylaxis is associated with persistent protection against candidiasis-related death in allogeneic marrow transplant recipients: long-term follow-up of a randomized, placebo-controlled trial. Blood. 2000;96:2055-2061.

59. Winston DJ, Pakrasi A, Busuttil RW. Prophylactic fluconazole in liver transplant recipients. A randomized, double-blind, placebo-controlled trial. Ann Intern Med. 1999;131:729-737.

\section{SUPPORTING INFORMATION}

Additional Supporting Information may be found online in the supporting information tab for this article.

How to cite this article: Andes, D.R., Safdar, N., Baddley, J.W., Alexander, B., Brumble, L., Freifeld, A., Hadley, S., Herwaldt, L., Kauffman, C., Lyon, G.M., Morrison, V., Patterson, T., Perl, T., Walker, R., Hess, T., Chiller, T., Pappas, P.G. and The TRANSNET Investigators (2016), The epidemiology and outcomes of invasive Candida infections among organ transplant recipients in the United States: results of the Transplant-Associated Infection Surveillance Network (TRANSNET). Transplant Infectious Disease, 18: 921-931. doi: 10.1111/tid.12613 